\title{
Pancreas - a Morphometrical Study in Large White Yorkshire and Desi Pigs
}

\author{
K. Iniyah ${ }^{1 *}$, S. Jayachitra ${ }^{1}$, K. Balasundaram ${ }^{1}$ and A. Arulmozhi ${ }^{2}$ \\ ${ }^{1}$ Department of Veterinary Anatomy, ${ }^{2}$ Department of Veterinary Pathology, Veterinary \\ College and Research Institute, Namakkal, TANUVAS, Tamil Nadu - 637 002, India \\ *Corresponding author
}

\begin{abstract}
A B S T R A C T
Keywords

Pancreas, Morphometry, Histometry, Pancreatic

lobe

Article Info

Accepted:

22 October 2018

Available Online:

10 November 2018

The pancreas, an important organ of endocrine research is a digestive gland with both exocrine and endocrine functions. The pancreas for this study was collected from different age groups of large white Yorkshire and desi pigs. The morphometrical parameters such as weight of pancreas, length and width of each lobe and histometrical parameters such as number of islets per lobule, length and width of islets were recorded. The pancreas of pigs consisted of splenic, duodenal and connecting lobes. The mean weight of the pancreas was gradually increased as age advanced. In proportion to body weight and pancreas weight, the length and width of pancreatic lobes were steadily increased from four months of age to adult. The number of islets per lobule was higher in young age groups and then gradually decreased with age. This morphometrical study of pig pancreas can serve as a standard to judge atrophy or hypertrophy of organs in post-mortem diagnosis and for research in pancreas of other species.
\end{abstract}

\section{Introduction}

The pancreas, an important organ for endocrine research in correlation with pancreatic disorders of diabetes is a unique digestive gland which consists of both exocrine pancreatic acini and endocrine islets of Langerhans. The transplantation of porcine islets of Langerhans is considered to be a possible alternative for clinical islet transplantation in humans (Hilling et al., 2009). Normal anatomic ranges of pancreas should be known to define the pathological conditions. As only a few studies have been performed regarding morphometry of pancreas, the present study was undertaken to gain the basic knowledge about the morphometry of pancreas of large white Yorkshire and desi pigs. The objective of this study is to determine gross morphometry and histometry of pancreas and explore their association with age and weight of the animal.

\section{Materials and Methods}

The pancreas for the study had been collected from large white Yorkshire and desi pigs which were slaughtered for the purpose of 
meat at local slaughter house, Namakkal and Department of Meat science, Veterinary College and Research Institute, Namakkal. The pancreas was collected from different age groups of large white Yorkshire and from adult desi pigs. Each group comprised of six samples of either sex. The pancreas was removed from the animal immediately after slaughter, washed in normal saline and mopped with blotting paper. Then the different lobes of pancreas were identified and utilized for the morphometrical study. The morphometrical parameters such as weight of pancreas, length and width of each lobe were recorded in large white Yorkshire from four months of age to adult and in adult desi pigs.

Then the pancreatic tissues were fixed in $10 \%$ neutral buffered formalin and processed using rotary microtome and stained with haematoxylin and eosin stain for histometrical study of endocrine part of pancreas (Bancroft and Stevens, 1996). Histometrical parameters viz., number of islets in each lobe, length and width of islets were recorded by using Leica image analyzer software. The morphometrical and histometrical observations were statistically analyzed as per the method of Snedecor and Cochran (1992) and the mean of various parameters of different age groups were compared.

\section{Results and Discussion}

\section{Morphometry}

\section{Weight of the pancreas}

The pancreas was located across the dorsal aspect of the abdominal cavity in both large white Yorkshire and desi pigs. The mean weight of the pancreas was recorded as 90.63 $\pm 1.31 \mathrm{~g}$ at four months, $113.50 \pm 3.47 \mathrm{~g}$ at six months, $124.28 \pm 1.21 \mathrm{~g}$ at eight months, $135.68 \pm 1.66 \mathrm{~g}$ at ten months of age and $161.58 \pm 2.86 \mathrm{~g}$ in adult large white Yorkshire pigs. Average pancreatic weight of $85.67 \pm$ $2.52 \mathrm{~g}$ was recorded in adult desi pigs (Table $1)$.

In contrary, Ferrer et al., (2008) recorded the mean weight of pig pancreas as $347 \pm 103 \mathrm{~g}$, with a range from 190 to $698 \mathrm{~g}$. The average weight of the pancreas was measured by various authors in different species viz., 350g in horse and cow (Frandson, 1974), 171g in camel (Ali and Masaad, 2007), 50-100g in dog (Frandson, 1974) and 95g in Indian donkey (Dhoolappa et al., 2004). This difference presumed that it might be due to variations in strain or nutritional status of the animal.

In large white Yorkshire, the mean weight of pancreas was gradually increased as the age advanced (Fig. 1) as reported by Ulrichs et al., (1995) in German landrace pig. The relative weight of the pancreas decreased from 0.24 to 0.14 per cent in young to adult large white Yorkshire and 0.13 per cent in adult desi pigs. But Dhoolappa et al., (2004) reported that in Indian donkey it was 0.175 per cent of body weight in adult.

\section{Dimensions of the pancreas}

The pancreas of large white Yorkshire and desi pigs consisted of three pancreatic lobes viz., splenic, duodenal and connecting lobe. The age wise length and width of splenic, duodenal and connecting lobes of pancreas in both the species were recorded (Table 2). The highest length and width of $13.50 \pm 0.41 \mathrm{~cm}$ and $6.31 \pm 0.69 \mathrm{~cm}$ in splenic lobe, $9.83 \pm$ $0.32 \mathrm{~cm}$ and $5.04 \pm 1.03 \mathrm{~cm}$ in duodenal lobe and $11.08 \pm 0.29 \mathrm{~cm}$ and $5.33 \pm 0.51 \mathrm{~cm}$ in connecting lobe were recorded in adult large white Yorkshire pigs respectively. The length and width of $11.18 \pm 0.33 \mathrm{~cm}$ and $4.74 \pm 0.26$ $\mathrm{cm}$ in splenic lobe, $5.82 \pm 0.55 \mathrm{~cm}$ and $3.56 \pm$ $0.44 \mathrm{~cm}$ in duodenal lobe and $8.37 \pm 0.35 \mathrm{~cm}$ and $3.67 \pm 0.50 \mathrm{~cm}$ in connecting lobe was recorded in adult desi pigs. 
Int.J.Curr.Microbiol.App.Sci (2018) 7(11): 2777-2781

Table.1 Morphometry of pancreas in different age groups of large white Yorkshire and desi pigs

\begin{tabular}{|c|c|c|c|c|c|c|}
\hline & \multicolumn{5}{|c|}{ Large white Yorkshire } & Desi pig \\
\hline & $\mathbf{4}$ months & 6 months & $\mathbf{8}$ months & 10 months & Adult & Adult \\
\hline $\begin{array}{c}\text { Body } \\
\text { weight }(\mathrm{kg})\end{array}$ & $38.46 \pm 2.24$ & $54.66 \pm 1.89$ & $72.23 \pm 0.85$ & $96.16 \pm 1.95$ & $117.60 \pm 1.43$ & $63.66 \pm 2.45$ \\
\hline $\begin{array}{c}\text { Pancreas } \\
\text { weight (g) }\end{array}$ & $90.63 \pm 1.31$ & $113.50 \pm 3.47$ & $124.28 \pm 1.21$ & $135.68 \pm 1.66$ & $161.58 \pm 2.86$ & $85.67 \pm 2.52$ \\
\hline $\begin{array}{c}\text { Relative } \\
\text { weight (\%) }\end{array}$ & 0.24 & 0.21 & 0.17 & 0.14 & 0.14 & 0.13 \\
\hline
\end{tabular}

Table.2 Morphometry of pancreatic lobes in different age groups of large white Yorkshire and desi pigs

\begin{tabular}{|c|c|c|c|c|c|c|c|}
\hline \multirow{2}{*}{\multicolumn{2}{|c|}{ Parameters }} & \multicolumn{5}{|c|}{ Large white Yorkshire } & \multirow{3}{*}{$\begin{array}{c}\text { Desi pig } \\
\text { Adult } \\
11.18 \pm 0.33\end{array}$} \\
\hline & & 4 months & 6 months & 8 months & 10 months & Adult & \\
\hline \multirow{2}{*}{$\begin{array}{l}\text { Splenic } \\
\text { Lobe }\end{array}$} & Length $(\mathbf{c m})$ & $8.02 \pm 0.35$ & $10.90 \pm 0.21$ & $11.07 \pm 0.23$ & $11.20 \pm 0.44$ & $13.50 \pm 0.41$ & \\
\hline & Width (cm) & $3.78 \pm 0.59$ & $4.79 \pm 0.30$ & $5.26 \pm 0.24$ & $5.32 \pm 0.36$ & $6.31 \pm 0.69$ & $4.74 \pm 0.26$ \\
\hline \multirow{2}{*}{$\begin{array}{l}\text { Duodena } \\
\text { I Lobe }\end{array}$} & Length (cm) & $6.20 \pm 0.16$ & $6.88 \pm 0.12$ & $8.07 \pm 0.11$ & $8.27 \pm 0.15$ & $9.83 \pm 0.32$ & $5.82 \pm 0.55$ \\
\hline & Width (cm) & $3.10 \pm 0.57$ & $3.78 \pm 0.47$ & $3.80 \pm 0.30$ & $4.59 \pm 1.12$ & $5.04 \pm 1.03$ & $3.56 \pm 0.44$ \\
\hline \multirow{2}{*}{$\begin{array}{l}\text { Connecti } \\
\text { ng Lobe }\end{array}$} & Length (cm) & $7.27 \pm 0.30$ & $7.84 \pm 0.29$ & $8.75 \pm 0.14$ & $9.33 \pm 0.17$ & $11.08 \pm 0.29$ & $8.37 \pm 0.35$ \\
\hline & Width (cm) & $3.76 \pm 0.45$ & $3.95 \pm 0.50$ & $4.12 \pm 0.58$ & $5.05 \pm 0.85$ & $5.33 \pm 0.51$ & $3.67 \pm 0.50$ \\
\hline
\end{tabular}

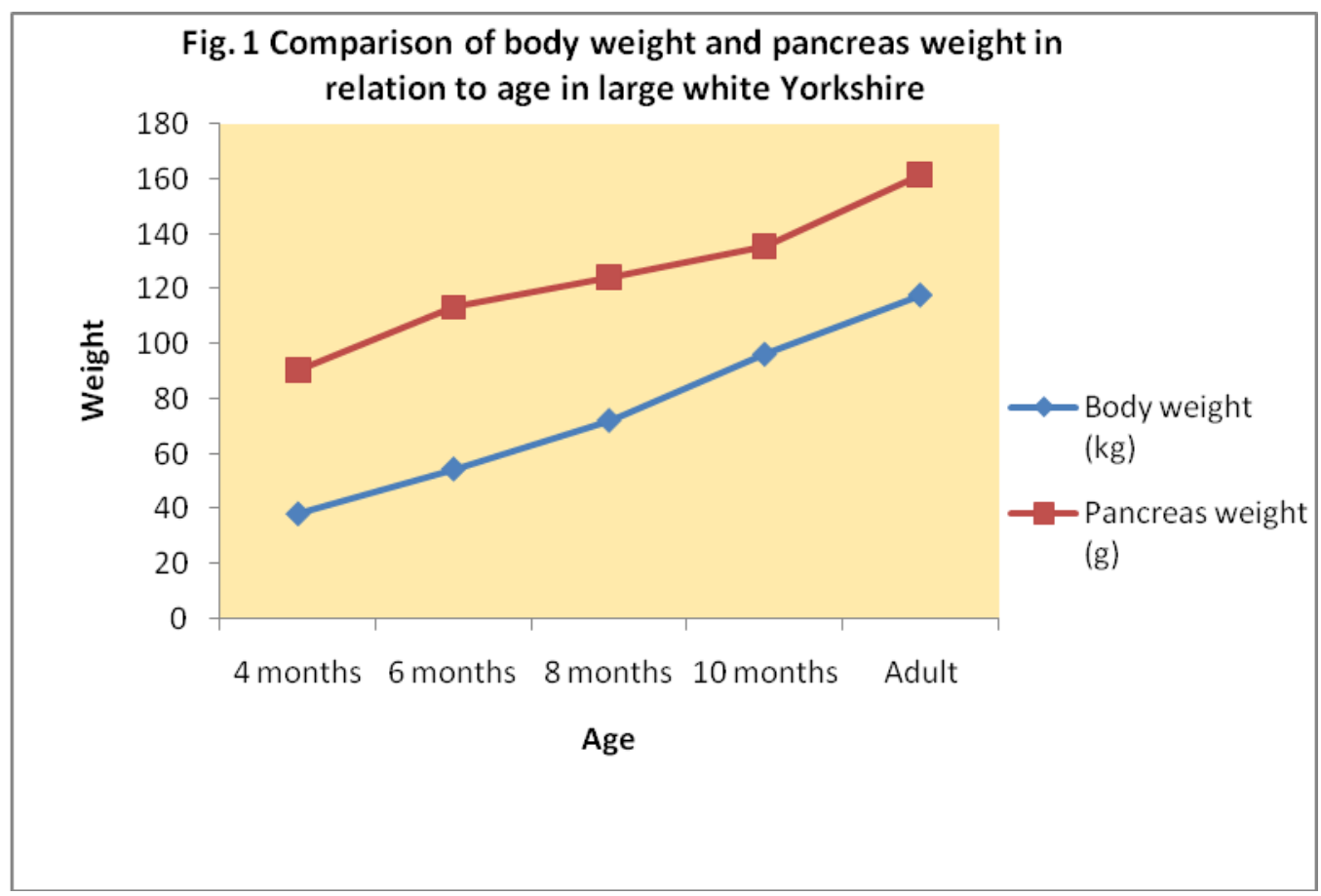




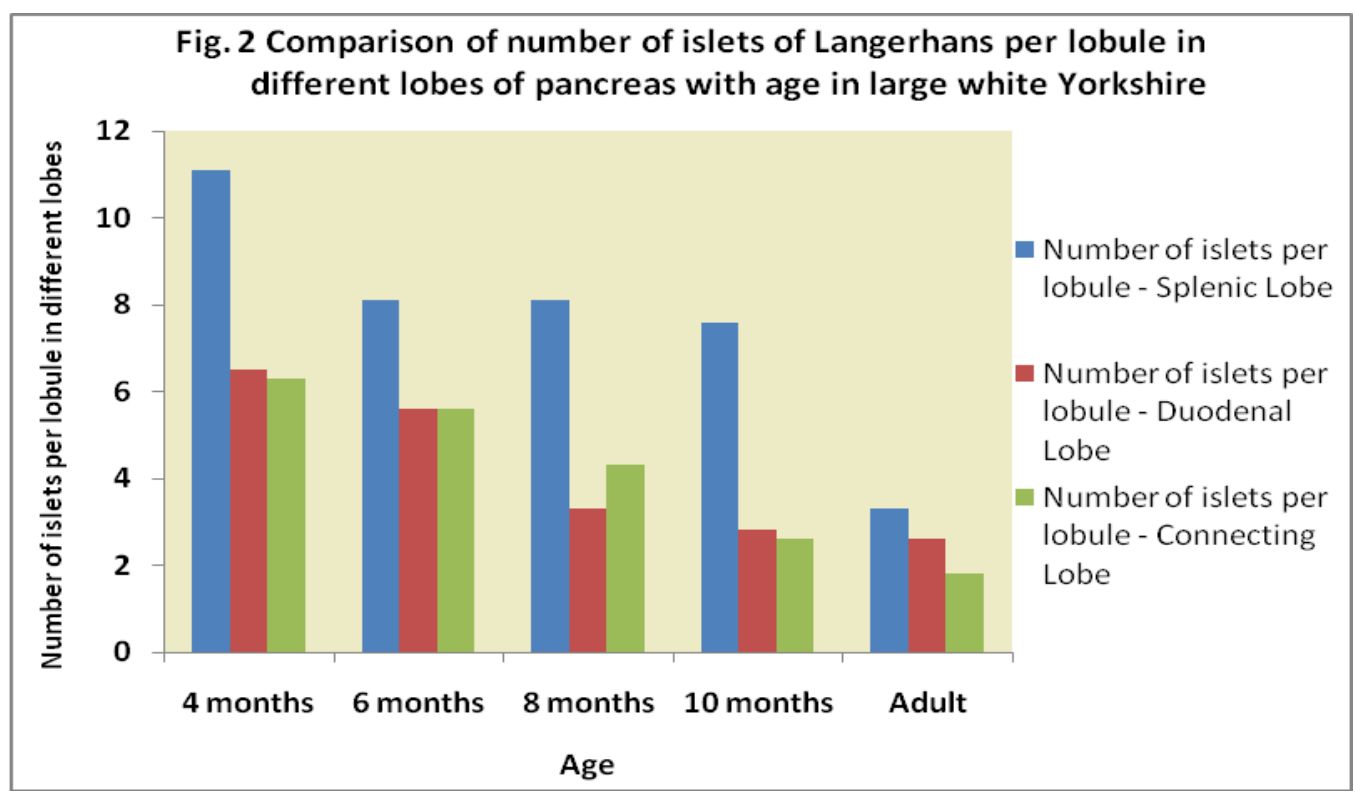

Whereas, Ali and Masaad (2007) mentioned that in camel, the length and width of right lobe, body and left lobe were $16.0 \mathrm{~cm}$ and $5.0 \mathrm{~cm}$, $10.0 \mathrm{~cm}$ and $4.0 \mathrm{~cm}, 29.0 \mathrm{~cm}$ and $5.0 \mathrm{~cm}$ respectively. Also recorded that the length and width of right lobe, body and left lobe as 10.0 $\mathrm{cm}$ and $7.0 \mathrm{~cm}, 7.0 \mathrm{~cm}$ and $6.0 \mathrm{~cm}, 16.0 \mathrm{~cm}$ and $6.0 \mathrm{~cm}$ respectively in donkey. These differences in dimensions of pancreas are attributed to age, breed and species variation.

In proportion to body weight and pancreas weight, the length and width of pancreatic lobes were steadily increased from four months of age to adult in large white Yorkshire. Among the three lobes, the length and width of splenic lobe was highest in all the age groups.

These morphometrical observations are not yet reported by any of the authors.

\section{Histometry}

The histometrical parameters of islets of Langerhans such as number of islets per lobule, length and width of islets were recorded for each lobe.

The average number of islets per lobule was recorded as $7.97 \pm 1.57$ at four months, $6.43 \pm$ 0.83 at six months, $5.23 \pm 1.46$ at eight months,
$4.33 \pm 1.63$ at ten months and $2.57 \pm 0.43$ in adult large white Yorkshire pigs. In adult desi pigs, it was observed as $3.20 \pm 0.47$.

The number of islets per lobule was higher in young age groups (Fig. 2) and gradually decreased as age advanced. In accordance Kinasiewicz et al., (2011) reported that the islet number per lobule was decreased as the body weight increased and Ulrichs et al., (1995) mentioned that the number of islet decreased with increase in age in pigs.

In large white Yorkshire, the mean length and width of islets were recorded as $121.53 \pm 2.05$ $\mu \mathrm{m}$ and $145.14 \pm 9.80 \mu \mathrm{m}$ at four months, 82.59 $\pm 12.83 \mu \mathrm{m}$ and $86.44 \pm 13.35 \mu \mathrm{m}$ at six months, $64.85 \pm 5.19 \mu \mathrm{m}$ and $110.29 \pm 6.51 \mu \mathrm{m}$ at eight months, $79.88 \pm 5.06 \mu \mathrm{m}$ and $35.07 \pm$ $20.25 \mu \mathrm{m}$ at ten months and 88.01 $\pm 3.92 \mu \mathrm{m}$ and $70.28 \pm 7.24 \mu \mathrm{m}$ in adult and was $56.44 \pm$ $17.40 \mu \mathrm{m}$ and $61.14 \pm 19.77 \mu \mathrm{m}$ in adult desi pigs respectively. But Prakash et al., (2014) mentioned that the length and width of large sized islets were $94.71 \pm 4.29 \mu \mathrm{m}$ and $48.00 \pm$ $2.79 \mu \mathrm{m}$ whereas for small sized islets, it was found as $51.36 \pm 3.96 \mu \mathrm{m}$ and $27.36 \pm 2.45 \mu \mathrm{m}$ respectively in the neonatal age group of Madras red sheep. In islets, the maximum length of $125.20 \pm 14.27 \mu \mathrm{m}$ in splenic lobe and width of $161.59 \pm 26.84 \mu \mathrm{m}$ in connecting lobe 
was recorded at four months of age in large white Yorkshire. This is in agreement with Mansouri et al., (2006) who stated that maximum diameter of islets of Langerhans was recorded in newborn mehraban female sheep.

In conclusion, the histo-morphometry of pancreas of large white Yorkshire and desi pigs revealed that the weight and dimensions of the pancreas, the number of islet per lobule, the islet length and width differs with age and weight of the animal. Thus this normal reference range of histo-morphometry of pancreas in correlation with age and weight of the animal can serve as a standard to judge atrophy or hypertrophy of organs in postmortem diagnosis and for further research findings in other species.

\section{References}

Ali, G. and G. A. M. Masaad, 2007. A comparative morphological study on the pancreas of the Dromedary (Camelus dromedarius) and the Donkey (Equus asinus). M.V.Sc., Thesis. B.V.M. University of Khartoum.

Bancroft, J. D. and A. Stevens, 1996. Theory and Practice of Histological Techniques. $4^{\text {th }}$ edn. Churchill Livingstone, Edinburgh, London.

Dhoolappa, M., A. Pawar, V. Ramakrishna and K. M. Gadre, 2004. Gross and histomorphology of Pancreas in donkey. Indian J. Anim. Sci., 74(9): 926-929.

Ferrer, J., W. A. Scott III, B. P. Weegman, T. M. Suszynski, D. E. R. Sutherland, B. J. Hering and K. K. Papas, 2008. Pig pancreas anatomy: Implications for pancreas procurement, preservation, and islet isolation. Transplantation, 86(11): 1503-1510

Frandson, R. D. 1974. Anatomy and physiology of farm animals. $2^{\text {nd }}$ edn. Lea $\&$ Febiger, Philadelphia.

Hilling, D., J. K. R. A. Rijkelijkhuizen, H. A. M. Tons, O. T. Terpstra and E. Bouwman, 2009. Amount and distribution of collagen in the pancreas have no effect on porcine islet isolation outcome. Transplant. Proc., 41(1): 326327.

Kinasiewicz, J., M. Sabat, M. AntosiakIwanska, E. Godlewska, E. Sitarek and T. Orlowski, 2011. The influence of porcine pancreas digestion parameters and islet histomorphology on islet isolation outcome. Pol. J. Vet. Sci., 14(2): 227-230.

Mansouri, S. H., S. Gholami and G. M. Orimi, 2006. Histomorphometrical study of pancreas in Mehraban female sheep. Iran. J. Vet. Res., 7(2): 14-19.

Prakash, P., S. U. Kumary, T. A. Kannan, G. Ramesh and S. H. Basha, 2014. Microanatomy of the Islets of Langerhans in the Pancreas of Madras Red Sheep (Ovis aries). Ind. J. Vet. Anat., 26(1): 4042.

Snedecor, G. W. and W. G. Cochran, 1992. Statistical Methods. $8^{\text {th }}$ edn. Iowa state university press. Ames.

Ulrichs, K., M. Bosse, A. Heiser, V. Eckstein, $\mathrm{H}-\mathrm{H}$. Wacker, A. Thiede and W. Ruchholtz, 1995. Histomorphological characteristics of the porcine pancreas as a basis for the isolation of islets of Langerhans. Xenotransplantation, 2: 176187.

\section{How to cite this article:}

Iniyah, K., S. Jayachitra, K. Balasundaram and Arulmozhi, A. 2018. Pancreas - a Morphometrical Study in Large White Yorkshire and Desi Pigs. Int.J.Curr.Microbiol.App.Sci. 7(11): 2777-2781. doi: https://doi.org/10.20546/ijcmas.2018.711.319 